\title{
LENGUAJE Y MORAL EN EL SIGLO XVII: LA CONTROVERSIA ENTRE JANSENISTAS Y JESUITAS
}

\author{
JAVIER PAMPARACUATRO MARTÍN \\ Universidad del País Vasco
}

\begin{abstract}
RESUMEN: Desde una perspectiva emic y de tiempo largo, este artículo examina una cuestión importante de la historia de las ideas religiosas: la controversia sobre moral que libraron jansenistas y jesuitas en el siglo XVII. A tal fin, aborda el estudio de tres obras del círculo de Port-Royal. En primer lugar, reflexiona en torno a la significación de la campaña de las Provinciales, conjunto de epístolas en que Pascal satiriza el laxismo que defendían en moral algunos jesuitas del siglo XVII. Por otra parte, estudia la estrecha unión de lenguaje y moral que llevó a cabo la doctrina de la Lógica y la Gramática de PortRoyal. El trabajo muestra que la abierta y enconada pugna que sostuvieron jansenistas y jesuitas con relación a sus respectivos programas antagónicos de teología, moral y lenguaje, y que se saldó con la derrota final de aquellos, escenifica y simboliza la sustitución de un mundo antiguo por otro nuevo, y prefigura el fenómeno que hoy llamamos crisis de la modernidad.
\end{abstract}

PALABRAS CLAVE: Provinciales; Pascal; laxismo; Logica y Gramática de Port-Royal; crisis de la modernidad.

\section{Language and Morals in the $17^{\text {th }}$ Century: The Jansenist-Jesuit Controversy}

ABSTRACT: Combining an emic and a long term approach, the present article examines an important issue of the history of religious ideas: the controversy on morals held by Jansenists and Jesuits in the $17^{\text {th }}$ century. With this aim in view, it considers three works of the Port-Royal circle. First, it reflects upon the significance of the campaign of the Provinciales, a series of letters in which Pascal satirizes the moral laxism that some $17^{\text {th }}$ century Jesuits defended in their writings. It also studies the close link between language and morals in Port-Royal's Logic and Grammar. This study shows that the open and bitter controversy kept by Jansenists and Jesuits regarding their two conflicting theological, moral and linguistic doctrines, and which ended up at the final defeat of the former, is the historical drama -and the symbol as well- of the substitution of an old order by a new one, and foreshadows the phenomenon known as crisis of modernity.

KEY WORDS: Provinciales; Pascal; laxism; Port-Royal's Logic and Grammar; crisis of modernity.

Rien n'est nouveau sous le soleil, et nul ne peut dire: Voilà une chose nouvelle; car elle a été déjà dans les siècles qui se sont passés avant nous.

(Ecclésiaste, I, 10)*

* La cita pertenece a la llamada Biblia de Port-Royal (v. Bibliografía), célebre traducción francesa de las Escrituras llevada a cabo por un grupo de sabios vinculados a Port-Royal, entre los cuales se hallaban Pascal, Arnauld y Nicole. 


\section{OвJEtivo}

El objetivo de este artículo no es meramente la narración y explicación de unos acontecimientos históricos. En primer lugar, no lo es por su enfoque transdisciplinar, que entrecruza historia religiosa y filosofía, pero, sobre todo, no lo es por el sentido último que lo anima. La razón para recordar aquí la pugna que, en el terreno teológico y moral, enfrentó a los jansenistas y a los jesuitas en el siglo XVII estriba en que aquel conflicto giró en torno a - y anticipó- actitudes hoy candentes en el ámbito cultural y social, actitudes que configuran el «nebuloso Zeitgeist que llamamos posmodernismo» ${ }^{1}$ : el relativismo; la desaparición de toda orientación normativa; la desfundamentación de los valores; la distorsión, reblandecimiento y debilidad de la razón y el lenguaje; la fragmentación moral (individualismo y narcisismo); la politización de todas las esferas de la vida. Los jesuitas laxistas que ridiculiza Pascal fueron los posmodernistas de la época. «Una ignorancia profunda sería mucho más deseable que tal saber, que enseña a considerar problemáticas todas las cosas» ${ }^{2}$. No hay, pues, nada nuevo bajo el sol. Lo que ahora parece novísimo es en realidad moneda antigua.

En suma, el trabajo se propone mostrar que la abierta y enconada pugna que sostuvieron jansenistas y jesuitas con relación a sus respectivos programas antagónicos de moral, teología y lenguaje, y que se saldó con la derrota final de aquellos, escenifica y simboliza la sustitución de un mundo antiguo por otro nuevo, y prefigura el fenómeno que hoy llamamos crisis de la modernidad. En este sentido, la visión adoptada en este artículo abarca, en alguna medida, la longue durée de las ideas.

Este artículo reflexiona en torno a la significación de tres obras del círculo jansenista: las Provinciales, de Pascal, y la Lógica y la Gramática de Port-Royal (La Logique ou l'Art de Penser, de Antoine Arnauld y Pierre Nicole, y la Grammaire générale et raisonnée, de Antoine Arnauld y Claude Lancelot).

\section{ConteXto: El JANSENISMO}

A fin de encuadrar adecuadamente las tesis de este artículo, resulta casi obligado componer una escueta visión general del jansenismo, sin entrar en complejidades ni sutilezas teológicas, en conexión con los principales hitos del que fue su principal bastión, Port-Royal.

Los jansenistas no se denominaban a sí mismos tales. Simplemente se consideraban agustinianos, discípulos de S. Agustín. Insistían en que no tenían nada nuevo que proponer, ya que se limitaban a seguir y a repetir la doctrina de la Iglesia tal y como se hallaba codificada en la teología agustiniana. S. Agustín, autoridad inconmovible que dominó en su conjunto la teología medieval, había insistido en la omnipotencia de la gracia, en la miseria y caída del hombre y en la cautividad a la cual el pecado original ha reducido a su libre arbitrio, no siendo, como consecuencia de

1 Sokal y Bricmont, 1999 [1998], p. 22.

2 Pascal, Écrits des curés de Paris, p. 410. 
ello, el hombre ya capaz del bien, sino propiamente del pecado y la mentira. Para el jansenismo la posición del hombre en S. Agustín es de total dependencia e insignificancia con respecto a su creador.

El jansenismo no es un fenómeno aislado, sino el último y exasperado intento de oponer resistencia a la crisis que el Renacimiento humanista provoca en la teología católica en el siglo $\mathrm{XVII}^{3}$. El jansenismo fue inicialmente una doctrina teológica que se exponía en el Augustinus (1640), pero a lo largo del tiempo fue adquiriendo nuevos aspectos (entre ellos, el rigorismo en moral). El Augustinus, obra del teólogo holandés Jansenio, obispo de Ypres, sistematizaba e interpretaba en su sentido más estricto la doctrina de S. Agustín acerca de la influencia de la gracia divina para hacer el bien (con mengua de la libertad humana). Según esta doctrina, el hombre, inevitable pero voluntariamente, obra el bien o el mal según se halle dominado por la gracia o por la concupiscencia, y no se puede resistir ni a la una ni a la otra.

Con el humanismo surgieron reivindicaciones nuevas. Los jesuitas, orden moderna por su situación intramundana y sus preocupaciones apostólicas, desempeñaron un papel decisivo en este momento. Muchos de ellos acusaban, con mayor o menor intensidad, la influencia de la corriente humanista, y tendían a abandonar el pesimismo agustiniano, la visión sombría de la naturaleza humana que había caracterizado a la teología tradicional. Se inclinaban a pensar que el agustinismo restringía de modo excesivo la parte que le correspondía al hombre en el problema de su propia salvación, y buscaban una teoría que otorgara a este un lugar mejor ante Dios. Fue sobre todo a causa de los esfuerzos de los teólogos jesuitas como tomó forma paulatinamente una nueva teología en el conjunto de Europa, el molinismo ${ }^{4}$, que a la postre se impondría, convirtiéndose en doctrina oficial de la Iglesia católica. En cuanto a la moral, los jesuitas se habían propuesto convertir el cristianismo en una religión amable y fácil. Para ello, no dudaban en buscar soluciones de compromiso, transacciones entre lo divino y lo mundano que no distanciaran al creyente de su religión, y que encontraron su expresión en una abundante literatura casuística. Para ellos, la teología había de ser todo lo elástica que fuera preciso para adaptarse a las demandas de la gente; podía interpretarse de distintas maneras con tal de lograr que el individuo no abandonara su religión alegando que su yugo es demasiado duro de soportar (Ex opinionum varietate jugum Christi suavius deportatur $)^{5}$.

Cognet y Delumeau, 1989, p. 884.

4 Recibió el nombre de molinismo el sistema recogido en el famoso tratado De concordia liberi arbitrii cum divinae gratiae donis (1588), del jesuita Luis de Molina. En él se mostraba una visión de conjunto de las nuevas ideas.

5 «Por la diversidad de opiniones (en moral) el yugo de Cristo se lleva más agradablemente». Escobar y Mendoza, A., Universae Theologiae moralis Problemata, Lyon, 1652 (2 vols.), Pról. al vol. I. Citado, sin indicar procedencia, en: BuRY, 2009 [1920], p. 78. La cita continúa: «La Providencia ha querido en su infinita bondad que haya varios medios de salir bien librado en moral y que las vías de la virtud sean anchas a fin de que se haga realidad la palabra del salmista: Vias tuas, Domine, monstra me». Cit. en: Delumeau, 1992 [1990], p. 118. 
El Augustinus, no es de extrañar, fue atacado de inmediato por los jesuitas. El choque entre el jansenismo (o agustinismo) y molinismo verdaderamente «concernía a los fundamentos espirituales del cristianismo» ${ }^{6}$.

Los avatares del jansenismo durante el siglo XVII se identifican con la historia de Port-Royal des Champs. Esta abadía de monjas cistercienses, fundada en 1204 en las cercanías de París, entra en la historia en 1602. Entonces se convirtió en símbolo destacado de la reforma monástica, que se extendería a otros monasterios de la orden cisterciense. Port-Royal se inscribía así en el movimiento de renovación religiosa que caracterizó la Contrarreforma. Trasladada temporalmente la comunidad a París (1626), Port-Royal llegó a ser, a partir de 1635, centro de difusión y defensa del jansenismo, bajo el impulso y la dirección espiritual del abad de SaintCyran.

Saint-Cyran, amigo personal de Jansenio, se esforzó en propagar la doctrina teológica jansenista en Francia, con un estudio atento de sus consecuencias para la vida cristiana. Esto explica que se le tenga por fundador del llamado partido jansenista en ese país. Saint-Cyran era un director espiritual exigente: para recibir la Eucaristía pedía unas disposiciones casi excepcionales, y, en lo que respecta a la Penitencia, abogaba por diferir la absolución con objeto de despertar en las almas sentimientos profundos de contrición y reparación. Su doctrina aspiraba a propiciar grandes conversiones, para las que aconsejaba además una vida retirada del mundo. Desde un momento temprano, el jansenismo fue mucho más que una teología: muy pronto se presentó como un rigorismo en moral hostil a la atrición, a la recepción demasiado fácil de los sacramentos, y a toda moral relajada. Ello generó una mentalidad y una corriente de opinión favorables en la época. Así define Mesnard la espiritualidad de Saint-Cyran: «La afirmación de un cristianismo intransigente y total, que rechaza todo compromiso con el mundo. De ahí algunos juicios severos, e imprudentes, sobre la corrupción de la iglesia de la época y sobre el amoralismo político de Richelieu» ${ }^{7}$.

Hacia 1637, un grupo de relevantes figuras comenzó a instalarse en los jardines y cercanías del abandonado Port-Royal des Champs, para formar una especie de congregación laica, de vida austera y penitente, los denominados «solitarios» de Port-Royal, consagrados al estudio y la oración. El espíritu de Port-Royal estaba ya formado, pero alcanzó su mayor vigor durante aproximadamente los veinte años que siguieron a la muerte de Saint-Cyran (1643). Ese esplendor atrajo, además de a muchos fieles oscuros, a numerosas altas personalidades, y la comunidad portroyalista se extendió más allá del grupo parisiense de adeptos, ya que en todo el país se estableció una vasta red de partidarios, concentrada en especial en determinadas diócesis.

Centro de vida intelectual y religiosa, Port-Royal también es la historia de un conflicto con diversos brotes a lo largo de décadas. Aunque los port-royalistas declararon su fidelidad a Roma y rechazaron el cisma, a partir de 1650 recayó sobre el jansenismo una serie de condenas de la Iglesia. Igualmente fueron hostigados por el poder político. Primero Mazarino y luego Luis XIV estaban decididos a erradicar

6 Kolakowski, 1995, p. 67.

7 Mesnard, 1989, p. 757. 
este foco de resistencia potencial al poder monárquico. El inicio del reinado personal de Luis XIV (1661) inauguró una etapa de persecución inflexible. En 1661 se sometió a la firma de las religiosas de Port-Royal un formulario condenatorio de las proposiciones jansenistas. Su negativa motivó el primer choque de una serie que se prolongó durante años, hasta que en 1669 se concluyó un acuerdo entre Roma, el Rey y Port-Royal, la llamada Paz de la Iglesia. Este periodo solo fue un intermedio, que, sin embargo, dio a Port-Royal y a sus partidarios diez años de tregua y brillo. En 1679, tras la ruptura de la paz, se renovó la persecución. El fin llegó en 1710, cuando Luis XIV ordenó la demolición de los edificios, ya deshabitados, del monasterio.

La continuidad del jansenismo hay que buscarla en aspectos de orden humano y moral. Estos aspectos son, en primer lugar, «la concepción de un cristianismo profundamente exigente, que quiere ser vivido sin compromisos ni concesiones ${ }^{8}$, ejemplificado por figuras como Saint-Cyran. En segundo lugar, la firmeza con la que oponen a los absolutismos de la autoridad los derechos imprescriptibles de la conciencia personal, su autonomía, su inviolabilidad. Es la reacción que se observa en Saint-Cyran, cuando desafía el sistema político-religioso de Richelieu; la que se observa en la negativa a firmar el Formulario...

\section{La polémica de las ProvinCiales: antecedentes e inicio}

Para exponer la controversia entre jesuitas y jansenistas, me centraré en el comentario de Les Provinciales, de Pascal, un clásico de la literatura francesa. Redactadas en su mayor parte en 1656, las dieciocho cartas de que se compone la obra constituyen un panfleto que arremete contra la moral relajada, la morale relâchée, el laxismo en la moral: contra una moral que a Pascal le parece una monstruosidad contraria a las Escrituras y la tradición. "Laxismo» se convirtió en la polémica en equivalente de términos que no son de hecho sinónimos suyos: probabilismo, casuismo y moral jesuita. Si bien en principio inocente, el casuismo presentó unas formas degeneradas que son las que se hicieron famosas y las que quedaron inmortalizadas a través de la obra de Pascal $^{9}$.

En este trabajo, partiré de un enfoque emic, la perspectiva de los jansenistas «tal y como se vieron a sí mismos». La elección se basa en la idea de que un punto de vista supuestamente neutro y equidistante no es el único que permite alcanzar una comprensión auténticamente "histórica» de la controversia. Por otra parte, paradójicamente, a la postre se revela más parcial que un enfoque emic. Un enfoque emic que tenga en cuenta el tiempo largo, combinado con la reflexión filosófica sobre asuntos históricos, puede contribuir de forma más eficaz que un enfoque etic al esclarecimiento de algunas importantes cuestiones de la historia de las ideas:

8 Cognet, 1961, p. 124.

9 Kolakowski, 1995, p. 61. Según este autor, Pascal no siempre se mostró fiable, y a menudo fue injusto, al sugerir que «algunas opiniones ridículas de unos cuantos padres eran típicas de los escritos jesuitas, cuando la mayoría de los casuistas no eran «laxistas» en ningún sentido importante» (ibíd., p. 63). 
especialmente, aquella con la que he iniciado este trabajo - la crisis de la modernidad-, y además otras conexas con ella y entre sí que tienen que ver con la continuidad y durabilidad bajo distintas formas y a lo largo de siglos de ciertas ideas y teorías. En esta esfera entrarían aspectos como el origen filosófico, religioso y teológico, próximo y remoto, del probabilismo, su gestación y evolución, y finalmente su degeneración en el laxismo. La visión referida permite captar ese devenir y la complejidad y relevancia filosóficas de las cuestiones implicadas; permite asimismo comprender que el probabilismo se inserta en una tradición de «teología moral de tradición benévola», y, además, diferenciar el concepto de otros (tuciorismo, casuismo, probabiliorismo, etc.), situándolo en la adecuada relación con ellos ${ }^{10}$. En un nivel más profundo, la perspectiva adoptada tiene en cuenta también otras cuestiones que aquí solo puedo enumerar, en la esperanza de abordarlas en futuras investigaciones: singularmente, las evoluciones históricas por separado y/o fusionadamente de la tríada ockhamismo, molinismo y humanismo, y sus relaciones con las condiciones económicas, sociales y políticas cambiantes. A pesar de las fecundas posibilidades que entraña el estudio del desarrollo de los referidos movimientos de ideas, el presente trabajo únicamente se ha centrado en el análisis del momento en que estos cristalizan para formar lo que puede considerarse el primer precedente intelectual de la actual crisis de la modernidad.

El momento al que aludo se inicia con el auge del casuismo. Durante los siglos XVI y XVII se consagraron numerosas obras, tanto en los países católicos como en los protestantes (Alemania e Inglaterra), a los casos de conciencia. Esta afluencia de tratados de casuística respondía a un aumento de la demanda de expertos en moral planteada por conciencias escrupulosas e inquietas ante la creciente complejidad, cambios y novedades que presentaba la vida cotidiana. En el transcurso de la segunda mitad del siglo XVI, un buen número de casuistas, entre los cuales se contaban varios jesuitas, fueron admitiendo progresivamente soluciones cada vez más generosas, tolerantes o poco escrupulosas en lo moral, deslizándose hacia un laxismo contra el cual el Santo Oficio reaccionará con diversas condenas. Este laxismo se vio propiciado por el probabilismo, en el cual encontró un instrumento cómodo y su «infraestructura intelectual» ${ }^{11}$. El revolucionario principio del probabilismo, formulado por el dominico Bartolomé Medina en 1577, reza así: en moral, está permitido seguir una opinión probable, es decir, sostenida por autores serios, aunque la opinión contraria parezca más probable ${ }^{12}$. Hay que insistir en que, para el probabilismo, lo «probable» no es lo bien sustentado en indicios, sino lo «aprobable», lo que está apoyado por el testimonio y el texto de la autoridad (por la aprobación) ${ }^{13}$. Así, según los probabilistas, se puede seguir una línea de conducta recomendada por alguna autoridad, aun cuando la línea de conducta opuesta la aconsejen más autoridades, o de más peso. Una "revolución moral, de origen español», que tuvo como iniciadores a Medina y al jesuita Suárez ${ }^{14}$. Y que resultó triunfante, pues es

10 Esta es la labor de Delumeau (1992 [1990], pp. 97-129).

11 Ibíd., p. 121.

12 De Medina, B., Expositio in primam secundae D. Thomae Aquinatis, Venecia, 1602, q. 19, art. 6, p. 176. Cit. en: Delumeau, 1992 [1990], p. 119.

13 HaCKING, 1975, p. 24.

14 Delumeau, 1992 [1990], p. 117. 
«hecho histórico de gran importancia» ${ }^{15}$ el éxito de las tesis probabilistas a fines del siglo XVI y en la primera mitad del XVII. Esta corriente dominó en dicho período la práctica de la confesión y la enseñanza de la teología moral: «la mayoría de los moralistas [de la época] adoptan el probabilismo» ${ }^{16}$. La teología moral adquirió entonces la forma de recopilación de opiniones probables y de «resoluciones» de casos de conciencia. Entre los teólogos de la Compañía de Jesús, el probabilismo reclutó ardientes defensores, hasta el punto de que apareció a los ojos del gran público como la doctrina moral por excelencia del grupo jesuita. Desde el punto de vista de los jansenistas, señala Hacking, los probabilistas primero optaban por una línea de acción en razón de su conveniencia social y moral, y luego encontraban algún viejo texto que corroboraba ese proceder ${ }^{17}$. Esta doctrina constituyó el blanco de la sexta carta de las Provinciales.

Sin embargo, la campaña contra la moral de los jesuitas no era algo nuevo ${ }^{18}$. Ya la doctrina de los casuistas jesuitas sobre el tiranicidio - por citar tan solo el caso más célebre- había sido vivamente atacada, y en 1610, tras el asesinato de Enrique IV, la famosa obra de Mariana, De rege et regis institutione, fue censurada por la Facultad de Teología de París. En lo que se refiere a la oposición propiamente dicha al laxismo, aunque comenzó verdaderamente en 1640, Roma antes había censurado muchas obras de este género (por ejemplo, la Vraye Guide des curez, de Milhard, en 1602). La imbricación de laxismo, probabilismo y casuismo explica que los ataques a cada tendencia se solapasen significativamente. Tanto en Francia como en Roma se sucedían las condenas a principios como: «Debemos aprender la regla de nuestra fe de los antiguos Padres; pero, en cuanto a las costumbres, hay que extraerla de los autores nuevos ${ }^{19}$. Este principio y las obras inspiradas en él (los libros de, por ejemplo, el P. Bauny) — argumentaban las censuras-inducían a las almas al libertinaje y a la corrupción ${ }^{20}$. En consecuencia, dichos libros eran prohibidos. En este ambiente se desenvolvieron los ataques jansenistas contra la moral de los jesuitas. La doctrina de Jansenio no podía ser más opuesta a la corrupción de la fe y la moral que propagaban los escritos casuistas. En 1643 se publicaron dos escritos de un teólogo eminente de Port-Royal, Antoine Arnauld: el tratado De la Fréquente communion, y un opúsculo que significó la primera ofensiva de conjunto desde el medio católico, Théologie morale des jésuites extraite fidèlement de leurs livres. A partir de este momento, se hicieron dominantes los argumentos rigoristas contra la absolución fácil y la moral laxa. Pero el público aún no percibía de modo particular un carácter jansenista en los acontecimientos.

En no escasa medida debido la influencia del Augustinus, los teólogos de Francia y Países Bajos emprendieron conjuntamente la lucha contra el laxismo a través

15 Ibid., p. 120.

16 DTC (= Dictionnaire de Théologie catholique, Paris, Letouzey et Ané, 1902-1950, 15 t. en 30 vols.), art. «Probabilisme», t. XIII, col. 483. Cit. en: Delumeau, 1992 [1990], p. 120.

17 Hacking, 1975, p. 24.

18 Sigo aquí a Cognet (1992, pp. viii-xii) y a Delumeau (1992 [1990], pp. 101-102, 123).

19 Proposición del P. Cellot (v. n. 30) censurada, como la obra de la que proviene, por la Sorbona en 1641.

20 Estos son los términos en que la Asamblea del clero de Francia reunida en Mantes (1641) pronunció su condena a Bauny. 
de una serie de censuras a proposiciones extraídas de escritos de casuistas relaja$\operatorname{dos}^{21}$. La fecha clave en todo este proceso es 1656, año de la publicación de las primeras Provinciales. Con esta serie de escritos, el jansenismo sobrepasó sus círculos de adeptos y se transmitió a un público más amplio. La Théologie morale, de Arnauld, que inspiró ciertas páginas de las Provinciales, no había causado ni de lejos el impacto sobre la opinión pública que produjo años después la obra de Pascal. Las Provinciales fueron un factor decisivo en la disputa: «de la cuarta a la decimosexta, atacan en un tono nuevo, graduado desde la ironía a la vehemencia, los sofismas de los moralistas del compromiso ${ }^{22}$. Con ellos, el principio probabilístico que preside su discurso se adoba con nuevas capas de falacias: "Cuando se obra según una opinión probable — asegura Castro Palao, siguiendo a Tomás Sánchez-, se obra siguiendo la más probable. Porque la opinión más probable es que se puede obrar según la probable, olvidada la más probable» ${ }^{23}$. Seguir la doctrina de la opinión que se estima más probable, dice el mismo autor, es exponerse al asalto de mil escrúpulos, porque nunca se está seguro del curso de acción correcto y siempre se está obligado a cambiar la conducta, ya que unas veces se presenta como probable una opinión y otras veces la contraria ${ }^{24}$.

Los jesuitas, sintiendo que un público numeroso se estaba llevando una impresión muy desfavorable del laxismo, comprendieron que tenían que defenderse. A partir de ese momento, lanzaron toda una serie de invectivas contra los jansenistas en las que escaseaban las buenas razones y en las que abundaban los ataques personales. La disputa siguió por una y otra parte, intensificándose al mismo tiempo que la posición política de Port-Royal se hacía cada vez más delicada.

\section{Comentario de las Provinciales}

En la elaboración de las Provinciales ${ }^{25}$, Pascal se basó en documentación procedente de obras de autores jesuitas, siendo la principal el Liber Theologiae moralis (1644), de Antonio Escobar, compilación en que se resumía lo esencial de la casuística jesuita. Luego, a medida que la campaña se desarrollaba, la documentación incluiría a autores más extravagantes y grotescos. La utilización que hace Pascal de los textos es, para los estándares de la época, extremadamente precisa, aun teniendo en cuenta que las traducciones que realiza de los pasajes en latín son

21 Entre los acontecimientos que han jalonado este movimiento de oposición al laxismo que se está resumiendo aquí pueden recordarse, además de los ya mencionados: la inclusión en el Índice de tres obras del P. Bauny (1640), la reprensión y represión al jesuita Airault por parte del Consejo del Rey (1644), las censuras de la universidad de Lovaina a la proposiciones del P. Amico (1649) y a diecisiete fórmulas pertenecientes a diversos autores laxistas (1653), la prohibición que el capítulo general de los dominicos impuso en Roma a los religiosos de la orden de aceptar e infundir opiniones de este jaez (1656)...

22 Delumeau, 1992 [1990], p. 102.

23 De Castro Palao, F., Opus morale de virtutibus et vitiis, Venecia, 1702 [Lyon, 16311647], p. 5. Cit. en: Delumeau, 1992 [1990], p. 119.

${ }_{24}$ Ibíd., $1^{a}$ parte, tr. 1, disp. 2, punct. 2, p. 5. Cit. en: Delumeau, 1992 [1990], p. 118.

25 Cognet, 1992, pp. xxxix-xlii. 
adaptaciones del original y que muchos textos en cursiva no son citas exactas, sino resúmenes del fragmento utilizado ${ }^{26}$. Los textos de los autores jesuitas son, salvo algún error ocasional, presentados de manera fiel, su sustancia, respetada, y, en cuanto al sentido que les atribuye, está fuera de toda discusión. Los autores que Pascal cita están, por supuesto, casi todos ya olvidados, pero enumeraré algunos; además de Escobar, figuran citados y comentados en las Provinciales: Diana, Lessius (Leys), Amico, Layman, Filliutius (Filliucci), Caramuel, Vázquez, etc. ${ }^{27} 28$

A pesar de que Pascal renuncia, por prudencia y pudor, al tratamiento de asuntos como el regicidio, el aborto y la moral sexual, el número de temas que trata es ya suficientemente amplio. Y de fondo, la preocupación del autor es asegurar el triunfo de las ideas teológicas agustinianas sobre el molinismo, la doctrina teológica rival defendida por la Compañía de Jesús. En un estilo incisivo y brillante, la obra maestra de Pascal aborda, pues, temas no solo morales, sino también teológicos. Si en estos, en los que no puedo entrar, se defiende de las censuras de los jesuitas que acusaban a los jansenistas de herejes; en lo que respecta a los asuntos morales, es Pascal quien ataca a aquellos por su laxismo.

El laxismo fue una tendencia moral desarrollada en el siglo XVII que tuvo como principales valedores a los jesuitas. Se apoya en el principio probabilístico para sostener que no existe pecado en una acción u omisión, si esta cuenta al menos con una probabilidad mínima de licitud. "Se puede hacer lo que se piensa que está permitido según una opinión probable aunque lo contrario sea más seguro. Porque la opinión de un solo doctor grave basta ${ }^{29}$, sentencia tempranamente, aún en el siglo XVI, el jesuita portugués Sá. De esta forma, se llegó —y de ello quedan los

26 Indico estos casos en las notas a las citas correspondientes.

27 Aclaremos que los laxistas Diana y Caramuel no pertenecían a la Compañía de Jesús. Antonino Diana, teatino italiano, fue conocido por su obra Resolutiones morales (1629-1659), que recoge resoluciones de casos de conciencia. En cuanto al cisterciense español Juan Caramuel de Lobkowitz, S. Alfonso María de Ligorio lo llamó «príncipe de los laxistas».

28 Por lo demás, en lo que se refiere a la acusación de que las citas están «a veces falseadas» (Delumeau, 1992 [1990], p. 105), resulta oportuno reproducir aquí la respuesta de Pascal a la pregunta de si había leído los autores citados en las Provinciales: «Respondo que no. Ciertamente, habría sido preciso que me pasara la vida leyendo libros muy malos. Pero a Escobar lo he leído dos veces entero, y, en cuanto a los demás, se los he dado a leer a mis amigos. No he empleado un solo pasaje sin haberlo leído yo mismo en el libro citado, sin haber examinado la materia sobre la que versa, y sin haber leído lo que precede y lo que sigue, para no arriesgarme a citar una objeción tomándola por una respuesta, cosa que habría sido reprochable e injusta» (Pascal, "Propos attribués à Pascal», p. 640). Además, las citas que Pascal reproduce abreviadas o parafraseadas se restituyen en la mayor parte de los casos en su integridad y literalidad y en la lengua original en la edición latina de Pierre Nicole (Wilhelm Wendrock [pseudón.], Ludovici Montaltii litterae provinciales de morali et politica jesuitarum disciplina..., e gallica in latinam linguam translatae, et theologicis notis illustratae, Colonia [i.e. Leiden], Nicolaus Schouten [i.e. J. Elzevier], 1658, 16654, 16795). Nicole, asimismo, completa las referencias, rectificándolas a veces, y añade largas notas explicativas. Del cotejo de ambas versiones se desprende que Pascal ha efectuado en ocasiones modificaciones en los textos, pero no tergiversación de su sentido.

29 De SÁ, M., Aphorismi confessariorum, Ruán, 1618 [Venecia, 1595], p. 183. Cit. en: PASCAL, Provinciales, p. 87 (traducción literal). ARnauld se refiere también a este texto (Théologie morale, p. 74). 
testimonios escritos de autores jesuitas que Pascal cita, resume, comenta, impugna y reprueba- a justificar todo tipo de acciones ilícitas: la simonía, la usura, la mentira, el adulterio, la calumnia (que se erige en sistema de defensa), el duelo, incluso el homicidio. Las probabilidades de licitud en materia moral las suministran las opiniones de los autores casuistas contemporáneos. Sus opiniones son preferibles a los antiguos Padres, aunque estos fuesen más próximos a los Apóstoles, porque los autores que las sostienen viven nuestros tiempos, y los Padres de la Iglesia vivieron en una época ya muy lejana ${ }^{30}$. De múltiples subterfugios y sofisterías de este tenor se abastece la sátira pascaliana. Mencionemos aún otro ardid: las contradicciones que los autores casuistas encuentran entre sus opiniones y las de los papas, los concilios y las Escrituras, las resuelven dictaminando que son aparentes e interpretando algún término para que encaje con el sentido deseado de la máxima moral que emiten. Las palabras, parece decirnos Pascal, torturadas convenientemente, pueden llegar a confesar cualquier cosa.

Es imposible no sonreír con la lectura de las Provinciales: con las citas de diversos escritores jesuitas, que siempre ofrecen una justificación a punto para todo tipo de crímenes y depravaciones, y por supuesto con los comentarios de Pascal. Me demoraré refiriendo una muestra de opiniones "probables» que hablan muy claro por sí mismas ${ }^{31}$.

Como he destacado, el vuelco que supone la moral laxista no se puede llevar a cabo sin retorcer al límite el lenguaje y el pensamiento. Le Moine enseñaba que, para que una acción constituya pecado, es necesario que Dios inspire en el alma el conocimiento de su debilidad, del médico que la debe curar, el deseo de curación, y el deseo de orarle e implorar su socorro. Así, según este autor, quienes viven al margen de Dios no pueden cometer pecado, y tienen, como irónicamente dice Pascal, su salvación asegurada. Escobar entiende por asesino solamente aquel que

30 Consejo de Reginaldus (Valère Regnauld) que repite Louis CELlot (De Hierarchia et Hierarchicis, RuÁN, 1641, Lib. 8, cap. 16, p. 714) y que es objeto de burla mordaz en la quinta provincial (Pascal, Provinciales, pp. 90-91), habiéndolo sido de crítica antes en la Theólogie morale des jésuites (ARnAuld, Théologie morale, p. 74).

31 Puesto que este artículo, como anuncié en sus primeras líneas, está animado por el afán de búsqueda de repetición de constantes en nuestros días, destacaré un paralelismo significativo de las Provinciales con una obra actual que ha alcanzado notable repercusión, Imposturas intelectuales, de Sokal y Bricmont. En un tono menos polémico y sarcástico, pero firme de todos modos, estos autores (científicos, como Pascal) citan determinados pasajes pertenecientes a teóricos posmodernistas con objeto de reprochar y satirizar en ellos el frecuente mal uso y extrapolación abusiva a las ciencias humanas o sociales de conceptos y términos científicos (o incluso pseudocientíficos). (Por «mal uso» entiéndase: uso ignorante, incompetente, superficial, incorrecto, incongruente, mistificador, injustificado, tramposo, prolijo y pedante). Lo que es más importante en nuestro contexto: Sokal y Bricmont, siempre mediante la transcripción y ridiculización de textos posmodernistas, denuncian, tanto el marcado sesgo político que imprime a la ciencia el posmodernismo como sobre todo el relativismo epistémico que este propugna, según el cual la objetividad, la racionalidad y la verdad son meras convenciones sociales. Los autores cuyos textos se recogen y comentan en el libro son: Jacques Lacan, Julia Kristeva, Luce Irigaray, Bruno Latour, Jean Baudrillard, Gilles Deleuze, Félix Guattari, Paul Virilio, Jean-François Lyotard, Jacques Derrida... Los mensajes de Provinciales e Imposturas confluyen a través de los siglos, así como el procedimiento para transmitirlos (con la salvedad de que, además, Sokal también recurre a la parodia). 
recibe dinero por matar a alguien a traición, de donde se sigue que aquellos que matan sin recibir recompensa, sino solo para hacer un favor a sus amigos, no se llaman asesinos. Dar limosna de lo que sobra es un deber, pero Vázquez interpreta este precepto de forma que nunca sucede que nadie tenga nada que sobre, ni siquiera los reyes, descargando así en la práctica a los más ricos de la obligación de dar limosna. Según Escobar y Diana, un religioso puede quitarse su hábito sin incurrir en causa de excomunión, si lo hace por un motivo vergonzoso, como ir de incógnito a un burdel. Otros dicen que solo hay simonía si, al comprar un beneficio eclesiástico, quien da el dinero no lo entrega como el precio del beneficio espiritual, sino solo como medio para mover a la voluntad del vendedor a conferirlo. Un juez puede recibir regalos de las partes en el ejercicio de sus funciones, en una serie de casos (que resultan ser todos los posibles). Según varios autores (Molina, Reginaldus —o Regnauld-, Filliutius, Lessius), el juez está obligado a restituir lo que ha recibido por hacer justicia - a menos que lo haya recibido por generosidad-, pero nunca lo está a devolver lo que ha recibido de un hombre a favor del cual ha dado un veredicto injusto.

No hay usura si el acreedor toma el dinero del deudor, no como exigido por la justicia, sino como señal de reconocimiento. Los bienes que han sido adquiridos por vía ilegítima, como el adulterio, son, sin embargo, poseídos legítimamente, y no hay obligación alguna de reintegrarlos: «Se puede disponer de lo que se recibe por homicidios, sentencias injustas, pecados infames, etc., porque su posesión es justa, y porque se adquiere el dominio y propiedad de las cosas que se ganan ${ }^{32}$. La pereza es un pecado mortal (pero, según Escobar, es raro que alguien caiga nunca en él, toda vez que la pereza es definida como tristeza por el hecho de que las cosas espirituales son espirituales, como sería, por ejemplo, la aflicción por que los sacramentos son la fuente de la gracia). A juicio del mismo Escobar, no hay obligación de cumplir las promesas, si no se tiene intención de obligarse al hacerlas, «de manera que, cuando alguien dice simplemente: "Lo haré", se entiende que lo hará si no cambia de voluntad, ya que no se quiere privar con ello de su libertad» ${ }^{33}$. El P. Bauny sostiene que a cualquier hombre le está permitido entrar en lugares de libertinaje para convertir a mujeres caídas, aunque sea muy verosímil que peque una vez que esté allí. En opinión de Filliutius, si una mujer de alta condición —lo mismo que la casada, la doncella y la monja- ejerce la prostitución secretamente, tiene derecho a percibir un precio más alto que la mujer pública, pues su cuerpo es mucho más valioso. El P. Barry dice que llevar siempre consigo un rosario o una imagen de la Virgen asegura la salvación eterna, no importa lo que se haga, y aunque se viva toda la vida en pecado mortal, tal es el mérito de esta devoción.

De manera significativa, Caramuel recalca que «es una opinión probable que no hay pecado mortal en calumniar falsamente para conservar el honor, ya que es

32 De Escobar y Mendoza, A., Liber theologiae moralis viginti quattuor Societatis Jesu Doctoribus reseratus, Lyon, 1644, 1659, p. 609. Cit. en: Pascal, Provinciales, pp. 144-145 (traducción ligeramente abreviada).

33 Escobar, Liber theologiae moralis, p. 369. Cit. en: Pascal, Provinciales, p. 165. No reproduzco la cita completa. 
sostenida por más de veinte doctores graves ${ }^{34}$. La mentira y el perjurio los laxistas se jactan de evitarlos con el recurso a la doctrina de los equívocos, según la cual «está permitido usar términos ambiguos, haciendo que se entiendan en un sentido distinto al que uno mismo los entiende» ${ }^{35}$, dice el jesuita Tomás Sánchez. Cuando dicha doctrina no basta, se recurre a la de las restricciones mentales. «Se puede jurar - explica el mismo autor- que no se ha hecho una cosa, aunque se haya hecho realmente, entendiendo para sí mismo que no se ha hecho cierto día, o antes de haber nacido, o sobreentendiendo alguna otra circunstancia parecida, sin que las palabras que se usan tengan algún sentido que lo pueda hacer conocer; y esto es muy cómodo en muchas situaciones, y es siempre muy justo cuando es necesario o útil para la salud, el honor o la hacienda ${ }^{36}$. No se puede considerar falsedad, porque, según defiende Filliutius, la cualidad de la acción la determina la intención. Además, Filliutius proporciona otra receta destinada a sortear la mentira: después de decir en voz alta "Juro que no he hecho eso», añadir en voz baja "hoy»; o, después de decir en voz alta "Juro», añadir en voz baja "que digo», para continuar diciendo en voz alta "que no he hecho eso».

$\mathrm{Si}$, de todas maneras, se ha pecado — «lo que no es pequeña proeza en estas condiciones ${ }^{37}$ - el confesor debe imponer una penitencia ligera, si el penitente declara que no aceptará una mayor y que prefiere aplazarla para el otro mundo y sufrir en el purgatorio todas las penas que le correspondan. Según el P. Bauny, un confesor estaría cometiendo un pecado mortal si negara la absolución a alguien que halle justificación en una opinión probable, siempre que sea sostenida por un autor serio de la Compañía, y eso aunque sea mucho menos probable que la contraria.

Quizá la carta más reveladora de las Provinciales sea la séptima, que obtuvo un resonante éxito. Mazarino y el joven Luis XIV la leyeron, para gran descontento del P. Annat, jesuita y confesor del Rey. En un meditado crescendo, Pascal va desgranando testimonios de padres jesuitas que justifican y autorizan a las claras la agresión y el homicidio. Reproduzco algunas citas que Pascal extrae de libros laxistas. A pesar de que el Evangelio ordena que no se devuelva mal por mal, prohíbe la venganza y prescribe el perdón de las ofensas, el jesuita Henríquez declara: «Se puede matar al que ha dado una bofetada, aunque huya, con tal de que se evite hacerlo por odio o venganza, y de que no se dé lugar con ello a homicidios excesivos y perjudiciales para el Estado» ${ }^{38}$. Y otro, llamado Azor: «¿Le está permitido a un hombre de honor matar a aquel que quiere darle una bofetada o un bastonazo? Unos dicen que no; y dan como razón que la vida del prójimo es más preciosa que nuestro honor, además

34 De Caramuel y Lobkowitz, J., Theologia moralis fundamentalis, Fráncfort, 1652, Fund. LV, § 6, p. 550. Cit. en: Pascal, Provinciales, p. 278 (traducción bastante libre). No reproduzco la cita completa.

35 Sánchez, T., Opus morale in praecepta Decalogi, Madrid, 1613, p. 30. Cit. en: Pascal, Provinciales, p. 164 (traducción abreviada).

36 Ibid. Cita exacta.

37 KolaKowsKI, 1995, p. 62.

38 Cita de Enrique Henríouez (Summa theologiae moralis, Salamanca, 1591, lib. 14, c. 10, n. 3) algo modificada por PASCAL, tomada de EscoBAR (Liber theologiae moralis, p. 120). Cit. en: Pascal, Provinciales, p. 123. No reproduzco la cita completa. 
de que hay crueldad en matar a un hombre solo para evitar una bofetada. Pero otros dicen que está permitido; y ciertamente lo encuentro probable, cuando no se puede evitar de otra manera; ya que, sin esto, el honor de los inocentes estaría continuamente expuesto a la maldad de los osados» ${ }^{39}$. «Está permitido matar a aquel que os dice: "Habéis mentido", si no se le puede reportar de otra manera ${ }^{40}$, afirma el P. Baldelle. Asimismo, es lícito el homicidio por murmuraciones. Una máxima de Lessius dice: «Si intentáis arruinar mi reputación con calumnias ante personas de honor, y yo no lo puedo evitar más que matándoos, ¿̇lo puedo hacer? Sí, según autores modernos, e incluso aunque sea verdadero el delito que divulgáis [...]. [E]1 honor es más valioso que la vida. Ahora bien, se puede matar para salvar la vida, luego se puede matar para salvar el honor ${ }^{41}$. Escobar y el propio Molina defienden que no comete pecado quien mata a un hombre que quiera robarle una cosa del valor de un escudo, o menos: «regularmente se puede matar a un hombre por el valor de un escudo, según Molina $»^{42}$. Tannerus (secundado por otros muchos) escribe: «les está permitido a los eclesiásticos y a los religiosos incluso matar para defender, no solamente su vida, sino también sus bienes o los de su comunidad» ${ }^{43}$. Amico defiende que, igual que a cualquiera, a un religioso le está permitido matar a un difamador para evitar el deshonor, cuando no haya otro modo de impedir que publique hechos escandalosos de su comunidad o de él mismo ${ }^{44}$. El único límite que los laxistas fijan a la puesta en práctica de sus «opiniones» es la razón de Estado: «Hay que tener cuidado de que el uso de esta norma no sea perjudicial para el Estado, ya que en este caso no se debe permitir» ${ }^{45}$. Si conceden que sus máximas apenas se deben llevar a la práctica, no es porque piensen ni por un momento que la ley de Dios prohíba los hechos que dichas opiniones consienten. Como observa

39 De Azor, J., Institutiones morales, Roma, 1600-1611, part. 3, p. 105. Cit. en: Pascal, Provinciales, p. 124.

40 Cita de Baldelle (Nicolas Baldelli) (Disputationes ex morali Theologia, 1637, 1. 3, disp. 24, n. 24) abreviada por PAScAL, tomada de EscoBAR (Liber theologiae moralis, p. 120). Cit. en: Pascal, Provinciales, 125.

41 Cita de Lessius (Léonard Leys) (De Justitia et Jure actionum humanarum, Lovaina, 1605) ligeramente abreviada por PASCAL, tomada de un texto de N. HéreAu (que figura en la $I^{r e}$ Requête de l'Université). Cit. en: PAScal, Provinciales, pp. 125-126. No reproduzco la cita completa.

42 Escobar, Liber theologiae moralis, p. 119. Cit. en: Pascal, Provinciales, p. 128 (traducción parafraseada pero exacta).

${ }_{43}$ Tanner, A., Theologia scolastica, speculativa et pratica, Ingolstadt, 1627, 2, d. 4, q. 8, d. 4, n. 76. Cit. en: Pascal, Provinciales, p. 129.

44 Salvando distancias, un elocuente eco actual lo hallamos en unas declaraciones del papa Francisco, jesuita. Días después de que se perpetrara el atentado contra el semanario satírico francés Charlie Hebdo, en enero de 2015, en que resultaron asesinados doce personas y heridas otras once, el Papa manifestó a los periodistas que lo acompañaban en el avión en relación con tales hechos: «Es verdad que no se puede reaccionar violentamente, pero si Gasbarri [colaborador del Papa], gran amigo, dice una mala palabra en contra de mi madre, puede esperarse un puñetazo... ¡Es normal! No se puede provocar, no se puede insultar la fe de los demás. No se puede hacer burla de la fe. No se puede. Tenemos la obligación de hablar abiertamente, de tener esta libertad, pero sin ofender». Con estas palabras justificadoras de la violencia frente a la provocación, se deja sin efecto, a la vez, el precepto evangélico y el derecho fundamental a la libertad de expresión.

45 Lessius, De Justitia et Jure actionum humanarum. Cit. en: Pascal, Provinciales, p. 127. 
Pascal, tales hechos los jesuitas laxistas los consideran permitidos en conciencia «y sin mirar más que la verdad en sí misma» ${ }^{46}$. La más permisiva moral se resuelve en la más constrictiva política, podríamos pensar desde una óptica actual. Si el único límite que se reconoce a la conducta no es moral sino político, si la razón de Estado se yergue como la unica et ultima ratio, ya no queda ninguna garantía de que no se vaya a acabar defendiendo la subordinación de todas las acciones humanas a ella.

\section{LA POLÉMica: DESARROLLO Y DESENLACE}

Es fácil deducir qué motivos subyacían a la propagación de esta poco o nada exigente moral. La salvación a tan bajo precio resultaba sin duda atractiva para la mayoría, o eso pensaban los jesuitas. La moral de héroes agustiniana (jansenista, rigorista) ni es ni podrá ser nunca para el hombre común, parecían razonar. Lo cierto es que los casuistas, no solo los laxistas, estaban preocupados por mitigar la inquietud y escrúpulos de las conciencias y por aliviar el peso de la confesión de los hombros de los fieles. La guía de un confesor amable y obsequioso era preferible a la supervisión de un acusador severo e inquisitivo. La cuestión, sin embargo, es hasta dónde está dispuesto el religioso a llegar; «los críticos — de ningún modo solo los jansenistas - objetaban que la astuta complacencia jesuítica [...] significaba en última instancia la casi total tolerancia al pecado» ${ }^{47}$. Lo que con ella se pretendía era impedir que los salones y la corte escaparan al control del clero, una pérdida de influencia que con la predicación de la moral rigorista agustiniana habría tenido más probabilidades de ocurrir.

Haciendo un inciso, resulta pertinente traer a colación que el laxismo obedeció a una motivación análoga a la que intervino en el propósito de los jesuitas de convertir a otros pueblos y culturas. Durante la famosa e interminable controversia de los ritos chinos (1631-1742), los jesuitas fueron acusados de fomentar entre los prosélitos en el Extremo Oriente actos supersticiosos e idolátricos ${ }^{48}$. Ciertas iniciativas suyas provocaron vivas discusiones con los misioneros dominicos y franciscanos. El propio Pascal recrimina que los jesuitas, "cuando se encuentran en países en que un Dios crucificado se tiene por locura, suprimen el escándalo de la Cruz y solo predican un Jesucristo glorioso, y no un Jesucristo sufriente: como han hecho en India y China, en donde han consentido a los cristianos la idolatría misma ${ }^{49}$. Si los jesuitas se habían extendido por todo el mundo, ello fue «gracias a la doctrina de las opiniones probables, que es el origen y la base de todo este desorden ${ }^{50}$. Siguiendo un método de adaptación misionera, toleraron - recuerda Kolakowskila infiltración de supersticiones, costumbres y lenguaje paganos en las ceremonias

$46 \quad$ Pascal, Provinciales, p. 126.

47 KolakowsKi, 1995, p. 66.

48 Lo que motivó originalmente el conflicto fueron los esfuerzos de los jesuitas, y especialmente del P. Matteo Ricci, que vivió en China de 1581 a 1610, por cristianizar el confucianismo y expresar la doctrina y las enseñanzas cristianas en vocabulario chino familiar al neófito.

49 Pascal, Provinciales, pp. 76-77.

50 Ibíd., p. 78. Cursiva del autor. 
cristianas, e hicieron dejación de la labor de instruir a los futuros conversos en dogmas fundamentales en el convencimiento de que resultaban para ellos demasiado difíciles de comprender o admitir ${ }^{51}$. De esta forma, el injerto del paganismo en el cristianismo produjo un culto híbrido que fue finalmente condenado por Benedicto XIV en 1742 con la bula Ex quo singulari, en la que, entre otras acusaciones, se tacha a los jesuitas de capciosos. Dos siglos más tarde, en 1939, Pío XII declaró lícitas aquellas prácticas prohibidas. Sin embargo, al margen de que, con la perspectiva que da el tiempo, resulte acertada la postura de los jesuitas en aquella disputa, sus motivaciones siguen siendo en cualquier caso un asunto vidrioso, al dar por sentado algo que en sí mismo es innegablemente problemático: que los principios espirituales y éticos son siempre dúctiles, y que el grado de esa ductilidad lo dicta la conveniencia. Pascal vio que, en toda esta cuestión, los jesuitas «disimulan su prudencia humana y política con la invocación a una prudencia divina y cristiana; ¡como si la fe, y la tradición que la sostiene, no fuera siempre una e invariable en todo tiempo y lugar!; ¡como si le correspondiera a la regla ceder para adaptarse a la materia que le debe ser conforme, y como si las almas, para purificarse de sus manchas, no tuvieran más que alterar la ley del Señor, en vez de que sea la ley del Señor, que es sin tacha y santísima, la que debe convertir a las almas y conformarlas a sus ordenanzas salvadoras! $\aleph^{52}$.

La polémica entre jansenistas y jesuitas, que en realidad nunca había languidecido, se avivó con motivo de los ataques contenidos en la obra de Pascal. La campaña de las Provinciales continuó, y atravesó distintas fases, pero lo que era manifiesto es que Pascal nunca encontró un interlocutor entre los jesuitas digno de él. En este sentido, el combate siempre fue desigual. A medida que se iban publicando las cartas, anónimamente, aparecían las respuestas y refutaciones de los jesuitas, violentas y llenas de dicterios contra las gentes de Port-Royal. La autoría de estos libelos, muy mediocres, nunca fue reconocida por los jesuitas. Las acusaciones que vertían - que consistían principalmente en culpar a los jansenistas de heréticos- fueron recogidas en otros escritos, algo más destacables, pero tan poco fundados como los anteriores. Señalemos, por ejemplo, las seis Impostures escritas por el P. Nouet - una serie de imputaciones de falsedad al autor de las Provinciales (aún desconocido), seguidas cada una de ellas de un avertissement compuesto de descalificaciones e insinuaciones malintencionadas e injuriosas-y el libelo Rabatjoie des jansénistes, probablemente del P. Annat.

La obra de Pascal fue compuesta en un clima de persecución. El autor se vio forzado siempre a ocultar su nombre, y sobre la impresión y publicación de las cartas, que se llevó a cabo a lo largo de meses, siempre gravitó el temor a una intervención de la policía. Entretanto, la situación en Port-Royal se agravaba inexorablemente, $\mathrm{y}$, conscientes de la falta de apoyos, los jansenistas decidieron poner fin a la larga campaña de las Provinciales con la publicación de la decimoctava y última carta.

En 1657, apareció anónimamente la revancha jesuita contra todos los ataques jansenistas: un libro titulado Apologie pour les casuistes contre les calomnies des

51 KolaKowsKi, 1995, pp. 66-67.

52 Pascal, Provinciales, p. 78. Cursiva del autor. Las palabras destacadas aluden a una cita bíblica (Sal 18, 8). 
jansénistes. Poco después se supo que su autor era un jesuita, el P. G. Pirot ${ }^{53}$. En la línea de Nouet y Annat, refutaba las interpretaciones de los textos de los casuistas dadas en las Provinciales. Pero, y esto es lo sorprendente, en otras, las más importantes, admitía plenamente el sentido que Pascal censuraba, y reivindicaba altivamente la legitimidad de ciertas soluciones, incluso las más escabrosas, formuladas por los casuistas: este era el caso de las proposiciones acerca del homicidio. La publicación de Pirot, surgida en un momento en que la controversia parecía debilitarse, fue particularmente inoportuna. Como era de esperar, la obra provocó un tumulto considerable. De nuevo, en la contienda participó Pascal, colaborando activamente en los Écrits des curés, la prolongación de las Provinciales. Sin embargo, esta vez no hubo peligro para Port-Royal, ya que fue el clero parroquial, vivamente conmovido por las Provinciales, el que realizó gestiones ante la Asamblea general del clero de Francia, reunida desde 1655, y asumió la responsabilidad de la polémica. Sorprende comprobar la facilidad con que Pascal pasa del estilo vibrante que había utilizado en las Provinciales al más contenido y convencional de los Écrits des curés.

La campaña se saldó de forma ambigua. Las Provinciales fracasaron política y teológicamente, es decir, no evitaron la persecución política y religiosa, pero atrajeron un buen número de adhesiones y en este sentido fueron un éxito rotundo. La Francia culta leyó y aplaudió la obra. Al mismo tiempo, las Provinciales favorecieron que la Iglesia condenara definitivamente el laxismo. Alejandro VII, en 1665-1666, e Inocencio XI, en 1679, estigmatizaron 45 y 65 proposiciones laxistas, respectivamente. En 1700, la Asamblea del clero francés condenó 127. Al leer hoy las fórmulas reprobadas, «nos quedamos perplejos. [...] Sorprende que directores de conciencia hayan podido sostenerlas" ${ }^{54}$. "Algunas tendían indiscutiblemente perchas a las conciencias relajadas ${ }^{55}$. Las condenas fulminadas entre 1640 y 1700 contra el laxismo y el probabilismo fueron seguidas de una oleada rigorista que, no obstante, al final acabó remitiendo por el impulso de un renovador, S. Alfonso de Ligorio (1696-1787). Aunque S. Alfonso dista mucho del laxismo y de las exageraciones probabilistas, él mismo insistió en que en materia de moral los jesuitas fueron siempre sus maestros ${ }^{56}$.

\section{El LENGUAJE y SU RELACión CON LA MORAL EN LA QUERELLA DE LOS JANSENISTAS Y LOS JESUITAS}

Un programa de moral y lenguaje antagónico al de los jesuitas laxistas se expone en dos obras escritas por relevantes figuras de la comunidad de solitarios de Port-Royal. Son la Grammaire générale et raisonnée (1676), de Arnauld y Lancelot,

53 COgnet, 1992, pp. lxv-lxviii.

54 Delumeau, 1992 [1990], p. 103.

55 Ibíd., p. 125. «[N] os sentimos tentados a dar la razón a Pascal» (ibíd, p. 103), observa Delumeau, un autor que se caracteriza por su intento de comprender las razones de los moralistas jesuitas.

56 Ibid., p. 133. 
pero sobre todo La Logique ou l'Art de Penser (1683), de Arnauld y Nicole, la famosa Lógica de Port-Royal. Ambos tratados tienen estrechos vínculos y se complementan.

La Grammaire defiende entre sus tesis que entre las exigencias de la razón y el comportamiento real de las lenguas se interponen algunos factores de interferencia que continuamente alteran la correspondencia del lenguaje con el pensamiento. La gramática general y razonada que Arnauld y Lancelot proponen «trata de referir todos los fenómenos lingüísticos aparentemente más aislados a un sistema de nociones fundamentales que los expliquen ${ }^{57}$, a «los verdaderos fundamentos del arte de hablar» ${ }^{58}$. Estos remiten a «lo que tiene de espiritual [el lenguaje]», ya que, según la Grammaire, "el conocimiento de lo que sucede en nuestro espíritu es necesario para comprender los fundamentos de la gramática ${ }^{59}$. La exigencia de la Grammaire «de postular una realidad lingüística profunda responde a la necesidad de arribar a un punto firme, a un absoluto lingüístico, que valga para todos los hombres y que permita, aun en las circunstacias más confusas e intrincadas, encontrar la claridad ${ }^{60}$.

En la Logique se aborda también la desviación del lenguaje con respecto al pensamiento, pero no desde una perspectiva abstracta, como en la Grammaire, sino desde la más concreta de la comunicación del pensamiento. La Logique emprende, no el registro de los modos en que funciona nuestro entendimiento, sino la eliminación, en el tránsito del pensamiento a la expresión lingüística, de todo rastro de irracionalidad y subjetividad. En clave actual, esta preocupación de la Logique puede expresarse de diversas maneras: «permitir a los hombres la comunicación en la forma más perfecta posible» ${ }^{61}$, «satisfacer la exigencia de intersubjetividad completa ${ }^{62}$, etc. Mientras en la Grammaire, el uso, la arbitrariedad de toda lengua, era el principal factor de opacidad del pensamiento, en la Logique los factores de «ruido» o perturbación comunicacional son múltiples y variados, y estructurados en distintos niveles. Con una perspectiva más vasta y compleja que en la Grammaire, en la Logique el lenguaje es analizado teniendo presente la variedad de sus usos, funciones y fines, y la abigarrada riqueza de sus determinaciones ${ }^{63}$.

Grammaire y Logique convergen en el propósito manifiesto de reconducir el lenguaje a los esquemas de la razón. Su atento análisis muestra cómo las palabras no son solo un instrumento al servicio de una razón prelingüística, sino también un medio que puede resultar opaco. La Logique prolonga las intuiciones de la Grammaire denunciando los errores debidos a la falta de atención a la distancia que separa al pensamiento de su realización lingüística. En el trayecto del interior al exterior acontece una corrupción, debida en parte al medio corpóreo que debe atravesar el pensamiento. Pero también debida al destino práctico que rige esta transición. Lo cual equivale a decir que nuestros discursos se orientan siempre a variados usos sociales que se ven contaminados por las pasiones, el amor propio, los prejuicios o la

57 Simone, 1992 [1969], p. 107.

58 Arnauld y Lancelot, GGR, Préface, p. 3.

59 Ibíd., II I, p. 26.

60 Simone, 1992 [1969], p. 120.

61 Ibid., p. 129.

62 Ibid., p. 125.

63 Ibid., p. 132. 
ignorancia; en otras palabras, el momento comunicativo está subordinado a instancias no exclusivamente, o al menos no estrictamente, declarativas o informativas (Arnauld y Nicole asumen la tesis agustiniana de que la finalidad del lenguaje es o enseñar o aprender $\left.{ }^{64}\right)$. La distorsión del medio lingüístico se produce en todos sus niveles, comenzando por el fundamental, el semiológico, y continuando luego en el semántico, sintáctico y pragmático. La atención a los distintos niveles del lenguaje constituye una novedad indiscutible de Port-Royal.

La doctrina port-royalista sobre el lenguaje está estrechamente relacionada con la «visión trágica» jansenista del mundo, que a su vez emana de la concepción de la radical corrupción y finitud del hombre y de su estado de caída, de inclinación irresistible al mal y al pecado. La mediación lingüística carga con todos los peligros y negatividad derivados de la naturaleza caída del hombre (que incluyen los correspondientes a la naturaleza condenada a utilizar un código imperfecto que desfigura el pensamiento). En la teoría sobre el lenguaje de la Logique, la tesis agustiniana de la «peligrosidad» de los signos ${ }^{65}$ se aúna con la intensa coloración moral saintcyraniana. El moralismo y el interés por el lenguaje constituyen objetivos inextricablemente unidos en la obra de Arnauld y Nicole. En esta característica fundamental del libro resuena el eco de Pascal: «Moral y lenguaje son ciencias particulares, pero universales» ${ }^{66}$.

Derivada de sus posiciones fundamentales, la tarea que se designa la Logique es el análisis lógico-lingüístico, que reconduce la proposición pronunciada lo más cerca posible de la pretendida, y una construcción de una teoría de la argumentación que ponga en guardia frente a empleos desviados del discurso lingüístico. La finalidad del despliegue analítico de la Logique es la elaboración consciente de técnicas para purgar el uso lingüístico de todos los motivos de confusión, de todas las posibilidades de abuso que contenga y de cualquier elemento accidental. La Logique se esfuerza por borrar las huellas que la naturaleza del hombre tiende a superponer en la comunicación, a fin de convertir a los códigos lingüísticos en instrumentos de una comunicación completamente neutra y racional ${ }^{67}$. Conscientes de que el discurso tiene efectos prácticos (por ejemplo, convencer), y que por ello lleva inscrita la posibilidad de error y engaño, Arnauld y Nicole tratan de encauzarlo hacia el ámbito del conocimiento, es decir, al ámbito declarativo. Esta operación ha de entenderse encuadrada en la fusión que realizan de teoría del conocimiento y de análisis del discurso: «La lógica es el arte de guiar bien la razón en el conocimiento de las cosas, tanto para instruirse uno a sí mismo como para instruir a otros» ${ }^{68}$. Asimismo, ha de comprenderse sobre el trasfondo del objetivo moral de los portroyalistas, al basarse su método en la necesidad de una reflexión previa en la que el espíritu descubre los motivos de sus tendencias, protege contra la influencia de las pasiones e impulsos, y frena todos los déreglements d'esprit que enturbian nuestro juicio. En Port-Royal, «[e]l amor a la verdad está invariablemente constreñido a

64 S. Agustín, De Mag. 1,1.

65 El descrédito del signo no tiene un origen agustiniano, pero con S. Agustín (De Mag. $9,25 ; 9,26)$ y la tradición patrística adquiere un particular acento, que herederá Port-Royal.

66 Pascal, Pensées, 912/720.

67 Simone, 1992 [1969], pp. 129, 132.

68 Arnauld y Nicole, LAP, Introduction, p. 37. Cf. n. 64. 
chocar contra los límites de la naturaleza humana ${ }^{69}$, comenta Simone. Finalmente, el análisis lógico-lingüístico y la teoría de la argumentación de la Logique descansan en la creencia en la razón humana como instancia que debe fundamentarse en la fe. Todos los afanes metódicos de la obra tienen como guía el logos humano, que se funda en el Logos divino. Por corrompida y disociada de la sabiduría que esté la naturaleza humana, o precisamente por ello, el hombre posee en la razón un instrumento de salvación.

El Logos fundante está ausente en los tratados y libelos jesuíticos de la época. En una de estas obras, su autor eludía prácticamente el deber de amar a Dios, concluyendo que: «Dios, al ordenarnos que le amemos, se contenta con que le obedezcamos en sus otros mandamientos ${ }^{70}$. De ahí los reproches de Pascal de no tener en cuenta la Palabra de Dios: las Escrituras, los Evangelios, la tradición encarnada en los Padres de la Iglesia. En realidad, la Compañía de Jesús cae en todos los errores que la Logique de Port-Royal trata por todos los medios de enderezar. Incurre, a sabiendas o no, en todos los empleos desviados del discurso lingüístico ${ }^{71}$, en los sofismas contra los que alertaba Port-Royal, confundiendo y confundiéndose, pervirtiendo, por tanto, el uso recto del juicio, la razón, el corazón (en sentido pascaliano), la conciencia moral. El resultado es que la separación entre, por una parte, el juicio y la razón, y, por otra, la proposición lingüística y el razonamiento, deviene un hiato insalvable en los tratados de moral jesuíticos, agravado por el carácter demasiado práctico, nunca declarativo o representativo, de ese discurso, que llegará en sus refutaciones contra los jansenistas a la injuria o la calumnia; nada más lejos, pues, de lo declarativo.

Pero, si no hay Logos fundante, ¿qué hay en su lugar en el discurso moral jesuítico? Hay verba, palabrería, alusiones y citas de autores contemporáneos, supuestamente prestigiosos, que remiten unas a otras, y que por tanto no fundamentan ni pueden fundamentar nada. «Estos libros - dice Pascal- no hacen otra cosa que copiarse unos a otros ${ }^{72}$. Se desemboca así, desde esa intertextualidad, en lo que hoy llamaríamos relativismo, o incluso nihilismo. Porque, al fin y al cabo, solo se trata de encontrar otro autor que justifique (que haga probable, como ellos decían) cualquier aberración que se nos ocurra. Eso sí, bajo ciertas circunstancias y en determinados casos... Justamente, lo que le ha interesado siempre al poder político, el mismo poder político al que la Compañía de Jesús trataba de seducir y que soñaba con obtener. Un simpatizante de Port-Royal advirtió, en plena campaña de las Provinciales, lo siguiente: «Se tiene por deplorada y perdida la causa de los loyolistas, pero ellos resisten por otros principios. Les va bien en la Corte, en donde hacen de

69 SimONe, 1992 [1969], p. 129.

70 Sirmond, A., Défense de la vertu, Paris, 1641, pp. 18-19. Solo reproduzco el comienzo de un pasaje que Pascal abrevia y modifica ligeramente. Cit. en: PAscal, Provinciales, p. 189.

71 Un solo ejemplo: en clara impugnación a dichos usos, la Logique, basándose en la semiología aristotélica y agustiniana, establece cuáles son las condiciones básicas pragmáticas del signo lingüístico, entre las cuales figura la siguiente: «si bien cada uno tiene derecho a hacer un diccionario para sí, no lo tiene a hacerlo para otros ni a explicar sus palabras mediante las significaciones particulares que les haya conferido a los vocablos» (ARNAULD y Nicole, LAP, I XIV, pp. 93-94).

72 Pascal, Écrits des curés de Paris, p. 408. 
espías y de rufianes políticos, y aún mejor en Roma, donde llevan el agua a su molino, y donde el Papa es su cetro de bufón» ${ }^{73}$.

Una última observación acerca de la relación entre lenguaje y política puede ser relevante al mismo tiempo que ejemplificadora. Como he tratado de mostrar, en los escritos de los laxistas, las palabras se vacían de su contenido, y ello constituye parte esencial de su programa de lenguaje y moral. Desde el punto de vista de la moderna teoría pragmática de la comunicación, de la que fue precursora la Logique de Port-Royal, es este drenaje de «su último vestigio de significado e intención significativa [content meaning]» lo que convierte a las palabras «exclusivamente en instrumentos de predominio [one-upmanship]» ${ }^{74}$. El proceso por el cual se aniquila la lógica y la semántica se alza entonces como la posibilidad más inmediata de vencer en el espacio público y de lograr una posición de poder en él que permita consolidar tales usos disruptivos de la comunicación y por ende el poder mismo. En el siguiente apartado se comentará desde otro punto de vista esta quiebra del pensamiento y el lenguaje.

\section{CONSIDERACIONES Y CONCLUSIÓN}

Es sabido que el jansenismo fracasó. Pasando por alto las causas políticas de dicho fracaso, solo indico las de orden intelectual, que tienen que ver con el antihumanismo de Port-Royal. Con su adhesión al estricto teocentrismo agustiniano, el jansenismo - resume Cognet- iba a contracorriente de las tendencias humanistas del Renacimiento. Vinculándose desesperadamente con un pasado, del cual la Iglesia, si bien seguía afirmando su valor y legitimidad, cada vez se separaba más, se erigía para los tiempos venideros en el campeón de una causa ya perdida por inactual ${ }^{75}$.

Quizá por primera vez en la historia, la campaña de las Provinciales supuso una llamada consciente a la opinión pública, en la creencia, certera, de que ya constituía un recurso crucial para vencer en la controversia y así hacer prevalecer su concepción del cristianismo. Pero, aunque el jansenismo ganó las batallas de la opinión pública, perdió la guerra, porque no quiso o no supo entender (su moral tampoco se lo habría permitido, por otra parte) que las alianzas con el poder eran otra pieza fundamental para conseguir la victoria. Los jesuitas fueron en esa querella mediocres polemistas y peores escritores; sin embargo, lograron el triunfo de su doctrina teológica gracias a su carácter de orden intramundana, a su combinación de humanismo y cristianismo, a su transigencia con lo temporal, y sobre todo a su sed de poder e influencia. Navegaban con el viento de los tiempos a su favor, y

${ }_{73}$ Lettres de Guy Patin, p. p. J.-H. Reveillé-Parise, Paris, 1846, t. II, p. 253. Cit. en: Cognet, 1992, p. IV.

${ }_{74}$ Watzlawick, Beavin y Jackson, 1967, p. 82. One-upmanship es un término intraducible creado por un humorista inglés, Stephen POTTER (One-upmanship, Harmondsworth, Penguin, 1947). Es el «arte de llevar siempre la ventaja, arte de establecerse en una posición superior con respecto a otra persona (logrando una ventaja táctica en una conversación, etc.)» (Collins Diccionario inglés, $3^{\mathrm{a}}$ ed.).

75 Cognet, 1961, p. 126. 
además supieron situarse en la buena corriente. Se imaginaron que podían servir a dos señores. Nunca se mostraron renuentes a pagar un alto precio por esa ilusión: la perversión del lenguaje y la razón, y la consiguiente relativización o destrucción de los principios y valores cristianos. Siguiendo con la metáfora militar, los soldados de Cristo perdieron en aquellas hostilidades el combate contra el jansenismo, pues la moral laxista fue condenada, pero obtuvieron la victoria definitiva: históricamente, dentro de la Iglesia católica; pero también de modo simbólico, y no obstante más profundo y duradero, porque lo que representaron intelectualmente forma parte hoy de nuestra atmósfera cultural, configura nuestro Zeitgeist.

Aquellos tiempos prepararon, de una manera que aún está por estudiar, el advenimiento de los presentes. «Los laxistas estaban, en efecto, convencidos de pertenecer a una civilización en movimiento y a una edad nueva, donde se planteaban problemas inéditos y complejos, a los que los Padres no aportaban respuesta alguna ${ }^{76}$, resalta Delumeau. El probabilismo «contribuyó a modelar una moral mejor adaptada que la del pasado al ascenso de la civilización occidental» ${ }^{77}$. Diríamos desde un punto de vista contemporáneo que, al tratar de conciliar las exigencias de la vida moderna y las prescripciones de la moral cristiana, buscaba impedir que los cristianos se convirtieran en miembros de una civilización extinta, en rarae aves in terris. Esta preocupación ha de entenderse históricamente en términos de la confluencia de diversos factores, uno de los cuales vino representado por el humanismo. El probabilismo fue en el ámbito de la moral a la vez producto e instrumento de las nuevas corrientes humanistas al limitar la esfera de la obligación y de la obediencia a la ley para proteger el ámbito de la voluntad. El probabilismo concebía la moral primariamente al servicio de la acción y de las condiciones cambiantes de la vida, no de la reflexión y de la sujeción a leyes inmutables y eternas. Asombra ver con qué celeridad adoptó la faz de una moral relativista y descreída; con qué rapidez destejió lo laboriosamente tejido por la tradición moral durante siglos. No se puede evitar pensar que ese proceso constituyó un precedente para procesos análogos vividos en las últimas décadas en Occidente. Como ya se señaló, la explicación «desde dentro» de aquellos acontecimientos ayuda a entender cómo hemos llegado a los presentes.

La visión desarrollada aquí — una perspectiva emic - toma partido: ha sido «apasionada», y emite un veredicto moral. En lo que respecta al tono moralizante, este no solo no está de más, sino que a mi juicio es, en este caso, forzoso porque la posición moral que, alineándose con el agustinismo, estas páginas condenan constituye una versión ideológica y verbalizada, no por histórica y remota menos perfecta, del fenómeno conocido como banalidad del mal. Este es un asunto digno de un tratamiento aparte que aquí no es posible dar... Solo me limito a sugerir que en el laxismo jesuita se observa la superposición de las actitudes enumeradas al comienzo del artículo — que, en definitiva, apuntan a la pérdida del Logos - con la frívola permisividad del mal, que hace terminante el fracaso del pensamiento y el lenguaje, del logos: «la terrible banalidad del mal, ante la que las palabras y el pensamiento se sienten impotentes ${ }^{78}$.

76 Delumeau, 1992 [1990], p. 105.

77 Ibid., p. 121.

78 ARENDT, 2003 [1963], p. 366. 
En cuanto a la ausencia de neutralidad, puede objetarse que tal acercamiento es improcedente e inadmisible en historia entre otras razones porque el conocimiento histórico versa sobre acontecimientos «superados». En cierto sentido, efectivamente así es, porque la historia no vuelve a ser nunca la misma. No obstante, aun con variaciones, se repite de alguna forma, y es esta recurrencia, cuando nos toca de cerca, lo que nos impide tener una visión perfectamente «objetiva» acerca de determinados hechos. Así se entiende que lejanas realidades históricas se hayan convertido hoy en emblemas de constantes humanas fundamentales. Esta vigorosa y vigente carga de energía simbólica justifica — espero- el tono beligerante y la postura parcial del artículo.

La Compañía de Jesús (entiéndase, la de aquel momento histórico) es susceptible de ser interpretada sobre todo como metonimia de la banalidad del mal y de la crisis del Logos/logos, pero, además, es interpretable como figura de los correlatos que indefectiblemente acompañan a esos fenómenos: la pérdida de independencia de la vida y la conciencia, su supeditación a fines prácticos, su venalidad, su vulnerabilidad y fragilidad, su «politización». En el lado opuesto, para ilustrar el carácter emblemático de Port-Royal, valga esta cita de Mesnard: «lo que caracteriza a PortRoyal es cierto espíritu. Mientras que la mayor parte de la Iglesia católica, con los jesuitas marchando en formación, tomaba la vía de un compromiso entre humanismo y cristianismo, Port-Royal tendía a afirmar el absoluto de Dios, la nulidad del hombre sin Dios, la insignificancia de una sociedad sin Dios: actitud arcaica por su antihumanismo, moderna, por la promoción del individuo que indirectamente propiciaba. El choque de estas dos tendencias, la brutal persecución de que fue objeto la segunda, han hecho de Port-Royal un símbolo» ${ }^{79}$.

En esta época de aguda anomia, caracterizada por una conciencia desgarrada y en crisis, en fugaces ocasiones se ha vuelto hacia Port-Royal, en un anhelo inútil de recomponer una concepción del mundo que se ha ido quebrando y disgregando en todos los órdenes, siglo a siglo, desde finales de la Edad Media y a partir del Renacimiento, hasta nuestros días.

\section{BibLIOGRAFÍA}

Agustín, San (1982). El maestro, en: Obras de San Agustín, vol. III, Obras filosóficas, edición bilingüe, introducciones y notas de Victorino Capanaga. Madrid: Biblioteca de Autores Cristianos, [389].

Arendt, H. (2003). Eichmann en Jerusalén: un estudio sobre la banalidad del mal. Barcelona: Lumen, [1963].

Arnauld, A. Théologie morale des jésuites extraite fidèlement de leurs livres, 1643, en: Euvres de Messire Antoine Arnauld, docteur de la maison et société de Sorbonne, t. XXIX, A Paris, \& se vend à Lausanne, Chez Sigismond d'Arnay \& Cie., 1775-1781. 42 vols. [Bruxelles, Culture et Civilisation, 1964-1967. 43 t. en 38 vols.].

Arnauld, A. y Lancelot, C. (1966). Grammaire générale et raisonnée ou La Grammaire de Port-Royal, édition critique présentée par Herbert E. Brekle, Stuttgart-Bad Cannstatt, Frommann-Holzboog, [1676].

79 Mesnard, 1989, p. 756. 
Arnauld, A. y Pierre N. (1965). La Logique ou l'Art de Penser, édition critique par Pierre Clair et François Girbal. Paris: Presses Universitaires de France, [1683].

Bible de Port-Royal (1990). La Bible. Traduction de Louis-Isaac Lemaître de Sacy. Paris: Robert Laffont.

Bury, J. (2009). La idea del progreso. Madrid: Alianza, [1920].

Cognet, L. (1961). Le jansénisme. Paris: Presses Universitaires de France («Que sais-je?»).

Cognet, L. y Delumeau, J. (1989). «Jansénisme», en: Encyclopcedia Universalis, vol. XII, pp. 884-886, Paris.

Cognet, L. (1992). «Introduction» a: Pascal, Les Provinciales. Paris: Bordas.

Delumeau, J. (1992). La confesión y el perdón: las dificultades de la confesión, siglos XIII a XVIII. Madrid: Alianza, [1990].

Hacking, I. (1975). The Emergence of Probability: A Philosophical Study of Early Ideas about Probability, Induction and Statistical Inference. London: Cambridge University Press.

Kolakowski, L. (1995). God Owes us Nothing: a Brief Remark on Pascal's Religion and on the Spirit of Jansenism. Chicago: The University of Chicago Press.

Mesnard, J. (1989). «Port-Royal», en: Encyclopcedia Universalis, vol. XVIII, pp. 756-758, Paris.

Pascal, B. (1992). Les Provinciales ou Les Lettres écrites par Louis de Montalte à un provincial de ses amis et aux RR. PP. Jésuites, édition de L. Cognet et G. Ferreyrolles. Paris: Bordas, [1656-1657].

Pascal, B. (1992). Écrits des curés de Paris [1659], incluido en el vol. Les Provinciales. Paris: Bordas.

Pascal, B. (1976). Pensées, introduction de Dominique Descotes. Paris: Garnier-Flammarion, [1670].

Pascal, B. (1963). «Propos attribués à Pascal», en: Euvres complètes, préface d’Henri Gouhier, présentation et notes de L. Lafuma. Paris: Seuil.

Simone, R. (1992). «Introduzione», en: Grammatica e Logica di Port-Royal, Roma, Ubaldini, 1969, pp. viii-xlviii. Reed.: «Grammatica e logica di Port-Royal», en: Raffaele Simone, Il sogno di Saussure. Otto studi di storia delle idee linguistiche. Roma-Bari: Laterza, pp. 93132.

Sokal, A. y Bricmont, J. (1999). Imposturas intelectuales. Barcelona: Paidós, [1998].

Watzlawick, P. (1967). Janet Helmick Beavin y Don D. Jackson, Pragmatics of Human Communication: A Study of Interactional Patterns, Pathologies, and Paradoxes. New York-London: Norton.

Universidad del País Vasco

JAVier Pamparacuatro Martín

javier.pamparacuatro@ehu.eus

[Artículo aprobado para publicación en diciembre de 2016] 